\title{
Cost analysis of district heating compared to its competing technologies
}

\author{
O. Gudmundsson ${ }^{1}$, J. E. Thorsen ${ }^{1}$ \& L. Zhang ${ }^{2}$ \\ ${ }^{I}$ Danfoss A/S, District Energy Division, Application Center, Denmark \\ ${ }^{2}$ Department of Civil Engineering, Technical University of Denmark, \\ Denmark
}

\begin{abstract}
When talking about energy sustainability it is important to note that energy quality should be fitted to the intended use of the energy. Today, heat generation accounts for over $40 \%$ of the total energy use in Europe and only a minority of this heat is delivered by district heating.

As for energy quality and heating, space heating generally requires heat with energy quality of only $7 \%$ and domestic hot water requires energy quality of $15 \%$. It is therefore a complete waste of energy quality to serve these sectors with electricity, which has an energy quality of $100 \%$ or by burning fossil fuels in individual gas boilers. The alternative is to deliver low quality heat through district heating network to end users.

It is a common misunderstanding that district heating is an investment expensive technology. In this paper it is shown that the total investment costs are typically lower than for competing technologies. Due to the fact that district heating is invariant to the heat source it can easily be the cleanest heating option available and further, it provides the best possible means to match the energy quality to the energy need.

This paper will shed some light on: a) the investment cost when establishing district heating network for inner and outer cities; b) the cost of a few of the available heat sources for district heating; c) how district heating, cost wise, compares to other heating technologies available.

The main conclusion of the paper is that district heating is an important player in today's heat market and has the potential to be a key player in future energy
\end{abstract}


markets and provide the means to fulfil the ambitious green energy goals set forth in the European Union 20-20-20 goals.

Keywords: district heating, renewables, energy, efficiency, environmentally friendly, gas emissions.

\section{Introduction}

District heating is an economical and environmentally friendly way of distributing heat $(\mathrm{DH})$ to end users. The heat supplied in district heating is produced in an energy efficient way which has the potential to significantly cut greenhouse gas emissions.

In many countries, district heating has been actively promoted as an important component in the national strategic energy planning [1]. With the more and more stringent environmental regulation and the increasing awareness of energy security supply, the fossil fuel will be gradually phased-out and replaced by renewable energy. One of the features of $\mathrm{DH}$ is that it is invariant about the energy source. This feature of DH provide means to use low exergy sources like waste heat and renewable energy to match the low exergy demand for heating of buildings [2]. Due to this feature DH has the potential to play an important role in the future energy supply structure [3]. Heat sources for DH can be for example waste incineration [4], geothermal [5], solar thermal [6], biomass/gas [7], or through the combination of different renewable energy sources [8].

When it comes to space heating and domestic hot water (DHW) preparation there are few solutions available, however there is one that particularly stands out, district heating $(\mathrm{DH})$, due to its different nature compared to the rest. There are many benefits having a DH network, for example high efficiency, low $\mathrm{CO} 2$ emissions, indifference on fuel sources and possibility of using local heat/fuel sources [4-7], operational stability and many others. Further on it can be run on multiple heat sources which open up for optimal heat production for a given time [8]. Despite all the benefits of DH it is frequently overlooked by policy makers all over the world. The main reasons for this is perhaps due to high alleged initial investment costs, heat losses and the perception that buildings in Western Europe do not need as much heat as buildings in for example the Scandinavian countries. As for heat demands of buildings it has been shown that there is a remarkably little heat demand difference across Europe [9].

The common misunderstanding that $\mathrm{DH}$ is an expensive solution perhaps arises due to the fact that investment costs are typically funded by one identity instead of all house owners connected to the network, as it would be in case of decentralized heating solutions. The investments costs may therefore be hard to fund, especially if clear governmental policies are not available. In this paper it is shown that the cost of heat production in a DH network is lower than if decentralized heat production would be used. Furthermore DH allows usage of fuels that are not applicable for decentralized heat production, and it opens up for usage of waste heat from industry. By utilizing heat sources that are not applicable for decentralized heating solutions the matter of heat losses becomes arbitrary, this is especially true for utilization of waste heat. Further on heat 
losses in DH network are typically more than compensated by more efficient heat generation than in decentralized heating solutions. Investment costs stated in this analysis originate from Denmark and Sweden and are assumed to apply to other countries as well. Fuel costs are published average fuel costs for each of the countries this analysis looks on. All costs exclude VAT.

Today the most common heating options are, not necessarily in order of importance: a) district heating, b) solar thermal, c) gas/oil boilers, d) ground/air heat pumps and e) electrical heaters. All of those heating options have their pros and cons.

Option a) is independent on fuel source, has economy of scale, and gives the consumer the possibilities of varying capacity depending on consumers' requirements. With modern consumer installations and energy meters very high user control can be achieved for energy consumption.

Option b) is a decentralized option. The energy input is free solar power. The drawback is that it does not work if there is no sun and has therefore to be coupled to other heating options.

Option c) is a decentralized unit that is coupled to a gas grid, if available. The drawback is that the unit operates with combustion in consumer's houses which increases risk of fires. Additionally the units have a fixed capacity.

Option d) is an electrical driven process that moves heat from cold to hot location with high efficiency. The drawback is that it is using high grade energy, electricity, to operate.

Option e) fulfils the heating demand by electrical resistance. The drawback is that it is inefficient electrical heating compared to option d) and is using high grade energy.

\section{Base for calculation}

In this analysis a community of 3.000 buildings is investigated where an average floor area $120 \mathrm{~m}^{2}$ is assumed pr. consumer unit. It is no question that $\mathrm{DH}$ is economical for traditional houses so this analysis focuses on new low energy buildings with heat demands of $8 \mathrm{MWh}$ /year, thereof $3.2 \mathrm{MWh}$ are due to domestic hot water (DHW) consumption. It is assumed that peak demands $25 \mathrm{~W} / \mathrm{m}^{2}$. For capacity requirements the heat generation equipment needs to be sized to fulfill both space heating and DHW requirements, additionally it should include the expected heat losses at peak demand. In this analysis green field area is used for calculations. It is although noted that cost difference of setting up a $\mathrm{DH}$ network between green field area and prebuilt area is relatively small, as can be seen in Table 2 and [17].

In this analysis an annual discount rate of $7 \%$ is used in all calculations. The discount rate of $7 \%$ was chosen due to the long lifetime of the investments and small risks associated with the investments. Further on the time horizon in the calculations are related to the lifetime of components. 


\subsection{Cost calculation method}

For a fair comparison between different heating options it is necessary to take into account investment costs, operational costs, fuel costs and expected lifetime of the units. Investment costs are spread over the lifetime of the equipment using annualized cost calculations, Eq. (1).

$$
\text { Annulized cost }=\frac{W A C C}{1-(1-W A C C)^{\text {lifetime }}} * \text { Total Capex }
$$

where the $W A C C$ stands for Weighted Average Cost of Capital, or the interest rate that satisfies the owner, Total Capex stands for the total investment costs, cost of the unit + installation costs.

Additionally, the maintenance cost is taken into account for each unit, fuel cost and unit efficiency. The calculation flow chart is shown in Figure 1.

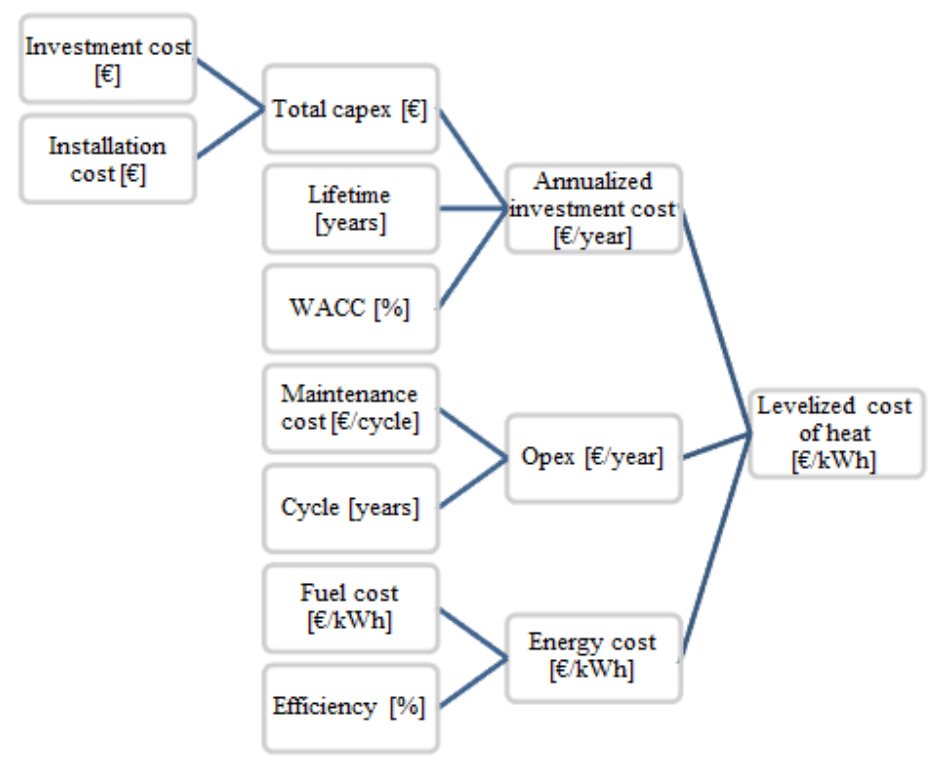

Figure 1: Calculation flow chart for calculating the levelized cost of heat.

It is assumed that all technologies use the same in-house distribution system, pipes and radiators. All technology costs are based on a report on the cost of decentralized heating units published by the Danish Energy Agency [10].

\section{District heating}

\subsection{Heat generation}

When it comes to a centralized heat process it should always be viewed in terms of the energy source and the environmental impacts it has. 


\subsubsection{Energy source}

Energy source for district heating can be any process that produces heat. Those can be power generation, industrial processes, solar thermal panels, biomass boilers, geothermal processes and etc. There are no requirements that energy sources should be from a single source. Energy can come from as many and as diversified sources as are economically available for a given district heating network. The benefit of having diversified energy sources feeding the DH network is that it gives the possibility of cost optimization depending on prices of each energy source, additionally it will result in more stable supply network.

Energy requirements are generally on a low grade, meaning that it is possible to use low quality energy sources. This is due to that space and DHW preparation do generally not require more than $55^{\circ} \mathrm{C}$ supply temperature in low energy buildings.

This also implies that district heating gives the option to use energy sources that would be hard to use decentralized without a thermal based distribution network.

By right choice of energy sources it is possible to minimize environmental impact compared to decentralized heat generation.

\subsubsection{Plant capacity}

When estimating the heat generation capacity required Eq. (2) can be used:

$$
\text { Plant capacity }=A_{\text {avg }}\left(D_{p}\left(1+N_{R}+E_{\text {peak load heat loss }}\right)\right) N
$$

where $A_{\text {avg }}$ is average house size $\left[\mathrm{m}^{2}\right], D_{p}$ is peak heat demand per square meter [W/ $\left./ \mathrm{m}^{2}\right], N_{R}$ is network reserve [\%], a network reserve of $8 \%$ is considered to be sufficient, $E_{\text {peak load heat loss }}$ is expected heat loss of network during peak load, which is considerably less than the average network heat loss, peak load heat losses of $5 \%$ are used for plant capacity calculations, and $N$ is number of buildings connected to the network [dimensionless]. Using above formula heat plant capacity for the case used in the analysis would be $10 \mathrm{MW}$.

\subsubsection{Heat plant investment costs}

Investment costs for different heat generation are taken from a Danish Energy Agency report [11]. Gas and electricity price used are from European Commission [12]. Cost information for wood chips for industry is from the report EUBIONET3 - WP3 - Wood fuel price statistics in Europe [13]. Heat plant costs can vary between plants and especially in case of a geothermal heat plant.

Further, it should be noted that there are a lot of other possible heat sources for $\mathrm{DH}$ that are not mentioned here due to lack of available cost data.

3.1.3.1 High temperature geothermal areas It is important to make clear distinction between low and high temperature geothermal areas. If utilization of high temperature geothermal area is possible, as in Iceland, it will provide very competitive energy prices. The Icelandic National Energy Authority has published 3 cost cases for geothermal energy in Iceland, cheap $(0,01 € / \mathrm{kWh})$, 
average $(0,014 € / \mathrm{kWh})$ and expensive $(0,028 € / \mathrm{kWh})[14]$. In all cases this is considerable less than what would be experienced in low temperature geothermal areas.

Geothermal energy is generally considered $\mathrm{CO}_{2}$ neutral and a renewable energy.

Table 1: Heat plant cost table.

\begin{tabular}{|c|c|c|c|c|}
\hline Heat plant type & $\begin{array}{c}\text { Specific } \\
\text { investment } \\
\text { costs }\end{array}$ & $\begin{array}{c}\text { Operating and } \\
\text { maintenance } \\
\text { cost }\end{array}$ & Efficiency & $\begin{array}{c}\text { Technical } \\
\text { lifetime }\end{array}$ \\
\hline $\begin{array}{c}\text { Centralized gas } \\
\text { boiler }\end{array}$ & $\begin{array}{c}0,06-0,12 \\
\mathrm{M} / \mathrm{MW}\end{array}$ & $\begin{array}{c}2-5 \% \text { of } \\
\text { investment } \cos t \mathrm{~s}\end{array}$ & $97-105 \%$ & 20 \\
\hline $\begin{array}{c}\text { Low temperature } \\
\text { geothermal }\end{array}$ & $\begin{array}{c}1,7-1,9 \\
\mathrm{M} / \mathrm{MW}\end{array}$ & $\begin{array}{c}2,5 \% \text { of } \\
\text { investment costs }\end{array}$ & $100 \%$ & 25 \\
\hline $\begin{array}{c}\text { Biomass boiler, } \\
\text { wood chips }\end{array}$ & $\begin{array}{c}0,3-0,7 \\
\mathrm{M} / \mathrm{MW}\end{array}$ & $\begin{array}{c}1,8-3 \% \text { of } \\
\text { investment costs }\end{array}$ & $108 \%$ & 20 \\
\hline
\end{tabular}

\subsubsection{Combined heat and power plants (CHP) and waste heat from}

industry During electricity generation in a power plant there will also be heat generation. Typically the electrical efficiency of a power plant is between 40$50 \%$, which is $40-50 \%$ of the energy in the fuel will be transformed to electricity and the remaining, $50-60 \%$, will be heat. Heat is typically of low quality and is in many cases dissipated into the atmosphere. However, heat can be used for space heating and DHW preparation. The price of heat in CHP plants should be priced so that it compensates for the lost power generation when producing heat as well. In the report Efficiency in Electricity Generation [15] the reduction of electricity production is approximately $14 \%$ when producing heat as well as power.

From this line of thinking cost of heat from CHP is typically assumed to be the lost revenue of the power, given a wholesale electricity price without TAX and distribution costs. In the report " 10 myths about the Danish electricity sector" [16], it is shown that cost due to electricity generation in 2012 was around $0.10 € / \mathrm{kWh}$ when supplied to the industry sector. If we assume that the electricity efficiency is $50 \%$ for power only plant and for CHP the electricity efficiency drops by $14 \%$, to $43 \%$, and further by assuming a thermal efficiency of $50 \%$ the cost of heat should be around $0.014 € / \mathrm{kWh}$. For simplicity the Danish case is considered representative for other countries for surplus and waste heat, this should be fair as Denmark has the highest gas price which is the dominant fuel in power production.

The $\mathrm{CO}_{2}$ impact of heat can be calculated similarly, which implies much lower $\mathrm{CO}_{2}$ impact of the heat than for equivalent electricity energy. 
In case of waste heat from industry $\mathrm{CO}_{2}$ impact of heat can be assumed to be zero, as heat is a waste/byproduct of the original process. For industrial waste heat the price should be considered to be the same as from a CHP plant.

\subsubsection{Alternative energy sources for district heating}

As district heating is not limited by a particular energy source it should be mentioned that energy could come from a variety of sources, for example: industrial sized thermal solar panels, excess electricity production (load shifting), excess heat from consumers that operate their own heating units or small industry like supermarkets.

If a seasonal heat sources are used, for example solar heat, a seasonal storage can be used to store the heat until needed.

\subsection{Distribution network}

The main uncertainty when establishing a district heating network is the initial investment in the distribution grid. Costs of the distribution network are highly dependent on the building to area ratio and heat demands. The higher the building to area ratio and heat demands are, the less the investment cost is per heat unit. This has been extensively studied and can be seen in [18].

By using the results in [18] capital cost of the distribution network can be estimated for variety of district heating cases, and especially for network with high energy sales per pipe meter per year (high linear heat density). It can, however, be more difficult to estimate the cost of networks with low building to area ratio.

Furthermore, the Swedish District Heating Association has introduced guidelines, [17], on how cost may be expected to vary between already established building areas and green field areas, where green field areas represents un-built areas. Green field areas are from 13-26\% less expensive than pre-built areas, depending on whether it is an inner city, outer city or a park area.

In case of low heat demands per consumer, for example in new buildings, network investment cost would decrease around $10 \%$ for each pipe dimension reduction, see [17]. This is, however, omitted in this analysis.

In Table 2 cost increases can be seen when going from green field areas to pre-built areas. Investment cost will although end in a relatively flat line when buildings start to rise vertically instead of getting closer together.

Table 2: Distribution network investment costs.

\begin{tabular}{|l|c|c|c|}
\hline $\begin{array}{c}\text { Type of } \\
\text { area }\end{array}$ & $\begin{array}{c}\text { Linear heat } \\
\text { density } \\
\text { GJ/m/y }\end{array}$ & $\begin{array}{c}\text { Investment cost, } \\
\text { green field area } \\
\text { €/house }\end{array}$ & $\begin{array}{c}\text { Investment cost, } \\
\text { prebuilt area } \\
\text { €/house }\end{array}$ \\
\hline Inner city & 15 & 1.400 & 1.950 \\
\hline Outer city & 10 & 1.600 & 2.050 \\
\hline Park area & 5 & 2.300 & 2.650 \\
\hline
\end{tabular}


It should be mentioned that as the heat density goes towards zero distribution network investments goes to infinity. As cost of installing district heating network pipes depends on many factors the values given in this analysis may not apply to all cases but should give a good starting point.

\subsection{Consumer installation}

Besides heat plant and distribution network it is required that consumers have a subscription interface, hereinafter substation, to the district heating network. This substation can be on different levels depending on the DH utility requirements; it can be either directly connected or indirectly connected. In the case of indirectly connected systems the building is hydraulically separated from the distribution network, different consumer installations can be seen in [19]. The prices of DH substations vary in relation to the requirements, on average it is $2,500 €$ with installation [10]. Operating and maintenance cost is assumed to be 150 euro/year. Lifetime of consumer installation is typically 20 years and has an efficiency of about $98 \%$.

Due to the diversity of heat sources and the benefits and limitation of a centralized heat production the DH case should be viewed for various cases.

Investment cost for district heating is for distribution network and consumer installation. For sake of comparisons the total heat cost in Table 3 is shown in euros per $\mathrm{kWh}$.

Table 3: Distribution grid and consumer installation cost per $\mathrm{kWh}$ and distribution losses for given heat density areas in a green field area.

\begin{tabular}{|l|l|l|r|}
\hline & \multicolumn{1}{|c|}{ Inner city } & \multicolumn{1}{|c|}{ Outer city } & Park area \\
\hline Low energy buildings & $0.050 € / \mathrm{kWh}$ & $0.051 € / \mathrm{kWh}$ & $0.060 € / \mathrm{kWh}$ \\
\hline Heat losses in network & $20 \%$ & $25 \%$ \\
\hline Low energy buildings & $10 \%$ & $2 \%$ & \\
\hline Heat loss in consumer installation &
\end{tabular}

\subsection{Energy losses}

\subsubsection{Distribution losses}

Distribution network plays a significant role in every district heating network. A poorly designed distribution network can cause high heat losses and inability to meet customers' demands, those things should be addressed during the planning phase.

In a modern district heating network the losses are typically in the range of $10 \%$; this will, however, depend on the linear heat density. In the case of high linear heat densities the heat losses can be below 5\% while in very low linear heat densities the heat losses could become as high as $25 \%$ [20].

In addition to heat losses there are hydraulic pressure losses in the distribution network. The pump energy consumption due to pressure losses are typically minor compared to the heat losses and are, therefore, neglected in this analysis. 
When considering distribution losses, it has to be kept in mind that the heat source is essential. In many cases the heat would have been lost to the full extent by not utilizing district heating. In cases where a waste heat source is located far from the consumer high heat loss in the distribution system can be accepted.

Table 3 shows the heat losses that are used for calculations in this paper; in a real situation the heat losses can be either higher or lower depending on the network.

\subsubsection{Heat losses in the building}

When it comes to the heat losses in the buildings it is assumed that for space heating the heat losses are equivalent between different heating technologies. However when it comes to DHW preparation it matters if the solution requires hot water storage tanks or not, generally district heating does not require storage tanks and for simplicity the assumption in the paper is that the decentralized heating solutions are dimensioned such that DHW is prepared instantaneously and no storage tanks are required, except in case of solar heating.

Total heat cost for various cases of DH setups can now be calculated using and the plant data presented above.

\subsection{Cost of district heating}

Using the data on heat plants, distribution network and substation costs given above, the total cost of heat for different district heating schemes is calculated by the procedure given in Section 2.1 above for various countries (see Table 4).

Table 4: $\quad$ Cost of heat from different DH schemes for low energy buildings in $€ / \mathrm{kWh}$.

\begin{tabular}{|c|c|c|c|c|c|c|c|c|}
\hline \multirow[b]{2}{*}{ Country } & \multicolumn{4}{|c|}{ Inner city } & \multicolumn{4}{|c|}{ Outer city } \\
\hline & Gas boiler & $\begin{array}{l}\text { Biomass } \\
\text { boiler }\end{array}$ & $\begin{array}{l}\text { Geothermal } \\
\text { plant, low } \\
\text { temperature }\end{array}$ & $\begin{array}{l}\text { CHP } \\
\text { Surplus / } \\
\text { waste }\end{array}$ & $\begin{array}{l}\text { Gas } \\
\text { boiler }\end{array}$ & $\begin{array}{l}\text { Biomass } \\
\text { boiler }\end{array}$ & $\begin{array}{l}\text { Geothermal } \\
\text { plant, low } \\
\text { temperature }\end{array}$ & $\begin{array}{l}\text { CHP Surplus / } \\
\text { waste }\end{array}$ \\
\hline Bulgaria & 0,091 & 0,109 & 0,142 & 0,066 & 0,097 & 0,117 & 0,155 & 0,069 \\
\hline Denmark & 0,126 & 0,109 & 0,144 & 0,066 & 0,137 & 0,117 & 0,157 & 0,069 \\
\hline Finland & 0,106 & 0,106 & 0,143 & 0,066 & 0,114 & 0,114 & 0,156 & 0,069 \\
\hline Ireland & 0,099 & 0,108 & 0,146 & 0,066 & 0,106 & 0,116 & 0,160 & 0,069 \\
\hline Italy & 0,094 & 0,097 & 0,149 & 0,066 & 0,100 & 0,104 & 0,163 & 0,069 \\
\hline Latvia & 0,092 & 0,104 & 0,145 & 0,066 & 0,098 & 0,112 & 0,158 & 0,069 \\
\hline Lithuania & 0,103 & 0,102 & 0,145 & 0,066 & 0,110 & 0,110 & 0,158 & 0,069 \\
\hline Portugal & 0,097 & 0,095 & 0,145 & 0,066 & 0,104 & 0,101 & 0,158 & 0,069 \\
\hline \begin{tabular}{|l} 
Slovakia \\
\end{tabular} & 0,100 & 0,107 & 0,146 & 0,066 & 0,108 & 0,115 & 0,160 & 0,069 \\
\hline Slovenia & 0,112 & 0,106 & 0,144 & 0,066 & 0,121 & 0,114 & 0,157 & 0,069 \\
\hline Sweden & 0,117 & 0,110 & 0,143 & 0,066 & 0,126 & 0,118 & 0,156 & 0,069 \\
\hline United Kingdom & 0,086 & 0,106 & 0,145 & 0,066 & 0,092 & 0,114 & 0,158 & 0,069 \\
\hline
\end{tabular}

\section{Comparison of different technologies}

\subsection{Decentralized heating technologies}

Table 5 shows the total cost of ownership for various decentralized heating technologies. Due to lack of data from other countries all costs and assumptions 
for decentralized heating technologies are from a report made by the Danish Energy Agency [10]. The heating equipment is dimensioned such it can fulfill peak heat demands. Gas and electricity price used are from European Commission [12], excluding VAT. Due to missing data on the gas price in Finland in the European Commission statistics the gas boiler is excluded for Finland. It is important to note that in the case of solar heating a theoretical full direct coverage is used, in reality this is not possible and it needs to be coupled with an alternative heating options. Further on the solar radiation is different between different locations, in this analysis the Danish case is taken as the base case for solar thermal. The coefficient of performance (COP) of heat pumps depends on the source temperature, which causes decreased COP for air source heat pumps on cold days.

Table 5: $\quad$ Cost of decentralized heating solutions in $€ / \mathrm{kWh}$.

\begin{tabular}{|l|c|c|c|c|c|}
\hline Country & Gas boiler & $\begin{array}{c}\text { Air source } \\
\text { heat pump }\end{array}$ & $\begin{array}{c}\text { Ground source } \\
\text { heat pump }\end{array}$ & $\begin{array}{c}\text { Solar } \\
\text { thermal* }\end{array}$ & $\begin{array}{c}\text { Electrical } \\
\text { boiler }\end{array}$ \\
\hline Bulgaria & 0,116 & 0,161 & 0,199 & 0,121 & 0,118 \\
\hline Denmark & 0,173 & 0,216 & 0,249 & 0,129 & 0,284 \\
\hline Finland & N/A & 0,173 & 0,210 & 0,122 & 0,156 \\
\hline Ireland & 0,129 & 0,193 & 0,228 & 0,125 & 0,216 \\
\hline Italy & 0,156 & 0,194 & 0,229 & 0,126 & 0,218 \\
\hline Latvia & 0,115 & 0,174 & 0,210 & 0,122 & 0,156 \\
\hline Lithuania & 0,123 & 0,170 & 0,207 & 0,122 & 0,147 \\
\hline Portugal & 0,141 & 0,188 & 0,223 & 0,125 & 0,199 \\
\hline Slovakia & 0,120 & 0,184 & 0,220 & 0,124 & 0,188 \\
\hline Slovenia & 0,148 & 0,178 & 0,214 & 0,123 & 0,170 \\
\hline Sweden & 0,180 & 0,191 & 0,226 & 0,125 & 0,209 \\
\hline United Kingdom & 0,128 & 0,187 & 0,222 & 0,124 & 0,196 \\
\hline
\end{tabular}

* Solar thermal needs to be coupled with other heating solutions as well to get full coverage.

\section{Conclusion}

Minimization of energy usage is a hot topic today, but it seems to be forgotten that energy comes in different quality. For example electricity is of highest quality while low temperature heat is of significantly lower quality, meaning that there are limitations on how the energy can be used. Energy quality can further be explained by the fact that high quality energy can be used in energy intense processes, for example melting metals while the low quality energy would hardly be able to melt metals, no matter the volume of low quality energy used for the task. Space heating works generally at low temperatures, and it should therefore 
use low quality energy and save high quality energy for processes that require high quality energy.

As can be seen from above the common assumption that $\mathrm{DH}$ is expensive compared with other technologies is simply not correct, not even for future low energy buildings. On the contrary DH is very competitive technology when looking on inner and outer city areas. This can be seen in the light that in an inner city area the initial investment cost, distribution grid per consumer and home installation are estimated to be around $3.900 €$ while a boiler dimensioned for equivalent comfort typically has initial investment cost of about $5.000 €$. In the case the building is not connected to a gas grid additional $2.000 €$ cost of gas grid connection should be added on top of the boiler cost. Other decentralized heating technologies typically have higher initial investment costs. It is, therefore, clear that the myth of high investment costs of DH is not true.

A centralized heat generation further allows for better control of environmentally unfriendly emissions through better equipment, professional operation and more efficient heat generation.

When comparing Tables 4 and 5 it can be seen that district heating is a very competitive solution for communities with heat densities that are comparable to inner and outer cities areas, especially if local waste heat from industry or a power plant is available. Due to high uncertainties when it comes to park areas feasibility studies should be carried out for each case.

It can clearly be seen that in case of low cost heat sources DH can be very well justified even in low heat density areas. Additional benefits are that DH runs on low exergy energy which matches the exergy need of the intended use of the energy.

In Denmark DH networks are commonly consumer or community owned and have no or minimum profit margin, but nonetheless according to the results there are substantial profit margins possible compared to decentralized solutions.

Benefits of district heating are not only related to cost, but the system also decreases environmental unfriendly gas emissions substantially and well beyond the targeted reduction in the EU 2020 targets. Due to the nature of district heating and indifference on energy source it can also fulfill the EU 2020 targets on reduction of primary energy consumption.

It is a common misunderstanding that $\mathrm{DH}$ is incompatible to future low energy houses. This paper and other studies as well proof that even with low energy consumption DH is a competitive solution, especially when run with heat from CHP plant or a waste heat from industry.

\section{References}

[1] Lund, H., Möller, B., Mathiesen B.V. and Dyrelund A., The Role of District Heating in Future Renewable Energy Systems. Energy, 35, pp. 35: 1381-90, 2010.

[2] Torio, H. and Schmidt, D., Development of System Concepts for Improving the Performance of A Waste Heat District Heating Network with Exergy Analysis. Energy and Buildings, 42, pp. 1601-1609, 2010. 
[3] Moller, B. and Lund, H., Conversion of Individual Natural Gas to District Heating: Geographical Studies of Supply Costs and Consequences for the Danish Energy System. Applied Energy, 87, pp. 1846-1857, 2010.

[4] Udomsri, S., Martin, and A.R., Martin, V., Thermally Driven Cooling Coupled with Municipal Solid Waste-Fired Power Plant: Application of Combined Heat, Cooling and Power in Tropical Urban Areas, Applied Energy, 88, pp. 1532-1542, 2010.

[5] Polyzakis, A.L., Koroneos, C.J., Malkogianni, A.K., Rovas, D.C. and Karmalis, J., Utilization of Geothermal Energy for District Heating and Cooling. Proc. of the WSEAS Conference, Spain, 2008.

[6] Larsen K., Heating and Cooling Europe with Solar. Renewable Energy Focus, 11, pp. 56-61, 2010.

[7] Rentizelas, A.A., Tatsiopoulos, I.P. and Tolis, A., An Optimization Model for Multi-Biomass Tri-Generation Energy Supply. Biomass and Bioenergy, 33, pp. 223-233, 2009.

[8] Faninger, G., Combined Solar-Biomass District Heating in Austria. Solar Energy, 69, pp. 425-435, 2000.

[9] Werner, S., The new European heating index. Proc. of the $10^{\text {th }}$ International Symposium on District Heating and Cooling, Hanover, 2006.

[10] Danish Energy Agency, Report: Individual Heating Plants and Energy Transport. Technology data for heating plants, Copenhagen, 2012.

[11] Danish Energy Agency, Generation of Electricity and District Heating, Energy Storage and Energy Carrier Generation and Conversion. Technology data for energy plants, Danish Energy Agency, Copenhagen, 2010.

[12] Electricity and natural gas price statistics; European Commission, eurostad. http://epp.eurostat.ec.europa.eu/statistics_explained/index.php/Electricity a nd natural gas price statistics, Date: 05.03.2013.

[13] Johan Vinterback and Charlotta Porsö, Report: EUBIONET3 - WP3 Wood fuel price statistics in Europe - D3.3, Uppsala, 2010.

[14] National Energy Authority. Report: Energy statistics in Iceland 2011, National Energy Authority, Reykjavik, 2011.

[15] Union of the Electricity Industry. Report: Efficiency in Electricity Generation, Union of the Electricity Industry, Brussels, 2003.

[16] Dansk Energy, Report: 10 punkterede myter om den danske elsektor, Dansk Energy, Copenhagen, 2012.

[17] Nordenswan, T., Report: Kulvertkostnadskatalog, Svensk Fjarrrvarme, Stockholm, 2007.

[18] Persson, U., and Werner, S. (2011). Heat Distribution and the Future Competitiveness of District Heating. Applied Energy, 568-576.

[19] Gudmundsson, O., and Thorsen, J. E., Danfoss Recommended solutions. Nordborg, 2012.

[20] Thorsen, J.E., Christiansen, H.H., Brand, M., Olesen, P.K. and Larsen, C.T., Experiences on low-temperature district heating in Lystrup Denmark. Proc. of the International Conference on District Energy, Slovenia, 2011. 